\title{
Prenatal and gestational cocaine exposure: Effects on the oxytocin system and social behavior with implications for addiction
}

\author{
S.K. Williams ${ }^{a}$ and J.M. Johns ${ }^{b}$ \\ aSection on Neural Gene Expression, National Institute of Mental Health, Bethesda, MD \\ ${ }^{b}$ Department of Psychiatry, Psychology and Curriculum of Neurobiology at University of North \\ Carolina at Chapel Hill, Chapel Hill, NC
}

\begin{abstract}
Drug abuse during pregnancy is a major public health concern, with negative consequences throughout development. Prenatal cocaine exposure (PCE) in rats produces social behavior deficits with corresponding changes in neuroendocrine and monoaminergic signaling. The relevance of parental care in social behavior maturity cannot be ignored, and gestational exposure to cocaine severely disrupts parental care, thus impacting the early environment of the offspring. Oxytocin (Oxt) is critical in regulating social behaviors and central levels are disrupted following acute and chronic cocaine (CC) treatment in postpartum rat dams, coincident with deficits in maternal care. We will discuss studies aimed to determine the relative contribution of PCE and $\mathrm{CC}$-induced deficits in maternal care to social behaviors and Oxt signaling across development. PCE results in decreased social (including parental) behaviors in adolescence and adulthood. PCE is also associated with increased aggression in adults. Rearing by CC-exposed mothers synergistically increases the behavioral effects of PCE. Rearing by CC-exposed mothers, but not PCE, disrupts Oxt levels and mRNA in regions relevant to social behavior, but does not affect receptors in postpartum adult offspring. Preliminary work indicates PCE/CC rearing has dynamic effects on Oxt levels and receptors in neonatal rat pups, suggesting very early regulation of Oxt signaling. This work highlights how the interactive role of Oxt signaling and behavioral context throughout development can be derailed by drug abuse during pregnancy. The relevance of disrupted Oxt to intergenerational transmission of addiction is briefly discussed.
\end{abstract}

\section{Keywords}

prenatal cocaine; oxytocin; maternal behavior; aggression; addiction; social behavior

\author{
(c) 2013 Elsevier Inc. All rights reserved. \\ Corresponding author: Sarah K. Williams 49 Convent Dr. Bethesda, MD 20892 Lab: 301-451-8332 Fax: 301-402-6473 \\ williamssk@mail.nih.gov.
}

Publisher's Disclaimer: This is a PDF file of an unedited manuscript that has been accepted for publication. As a service to our customers we are providing this early version of the manuscript. The manuscript will undergo copyediting, typesetting, and review of the resulting proof before it is published in its final citable form. Please note that during the production process errors may be discovered which could affect the content, and all legal disclaimers that apply to the journal pertain. 


\section{Introduction}

\subsection{Gestational drug exposure has direct and indirect effects on offspring}

Increasing evidence indicates many developmental and long-lasting neurological and behavioral effects following prenatal drug exposure (Williams et al., 2011b; Dow-Edwards, 2011; Lester et al., 1998; Lester and Padbury, 2009). Diverse pharmacological substances are known for their neurobehavioral teratological properties; however, prenatal cocaine exposure (PCE) remains one of the most investigated. In addition to the direct effects of drug exposure on the fetus, drug addiction during pregnancy can disrupt the mother's ability to care optimally for her child, and early dysfunctional maternal-infant interactions may compound negative effects of prenatal drug exposure (Williams et al., 2011b; Rutherford et al., 2011; Dow-Edwards, 2011; Strathearn and Mayes, 2010; Lester et al., 1998; Nephew and Febo, 2012; Lester and Padbury, 2009; Strathearn, 2011). Potential mechanisms that underlie the disruptions observed in women who abuse drugs during pregnancy remain elusive; although mounting evidence suggests the neuropeptide oxytocin (Oxt) may be an important contributor. Thus, the following brief review of relevant studies of cocaine's effects on mothers and offspring, highlighting Oxt as a mediating factor, may serve as a helpful guide for future studies.

\subsection{Clinical reports of cocaine-induced disrupted maternal care}

Chronic drug use and addiction can lead to disrupted parental care (Rutherford et al., 2011; Solis et al., 2012; Wells, 2009). Cocaine-using women are less engaged, less sensitive to infant cues, and have problems feeding their infants (Burns et al., 1991; Eiden et al., 2006; Tronick et al., 2005; Black et al., 1994; Minnes et al., 2005). Problems can persist with toddlers, with cocaine-using mothers exhibiting less interest and more hostility (Johnson et al., 2002; Suchman et al., 2010). Furthermore, these disruptions have been associated with changes in mood, stress response and lower plasma levels of Oxt (Light et al., 2004). Oxt dysregulation and it's interaction with brain reward and stress systems in mothers has been proposed as a likely moderator of neglectful behavior (Light et al., 2004; Strathearn and Mayes, 2010; Rutherford et al., 2011). Unfortunately, women who abuse cocaine often suffer from mood disorders, alcohol and nicotine use, and low socioeconomic status, which can all independently impact parental caregiving. Unfortunately, these drug-use associated parental behaviors result in children being placed in foster care at a rate 20 times higher than children from non-drug using homes (Eiden et al., 2007). These comorbidities make drawing distinct conclusions about cocaine use on parental care difficult in clinical populations.

\subsection{Preclinical reports of cocaine-induced disrupted maternal care}

Preclinical rodent studies that control for drug dose and regimen as well as gestational and postpartum environments, have allowed for more precise determination of the effects of cocaine on maternal behavior (MB) (see (Nephew and Febo, 2012) for review). Various cocaine treatment regimens ( $30 \mathrm{mg} / \mathrm{kg}$; acute, intermittent, or chronic) generally disrupt mother-infant interaction dynamics and increase infant neglect during the early postpartum period in the rodent with the extent of disruption dependent on dose, duration and postpartum day of testing (Nelson et al., 1998a; Johns et al., 1997b). Both acute (AC) and chronic cocaine (CC) treatments increased the latency to begin and decreased duration of nursing, reduced licking and nest-building behaviors, and generally disrupted initiation of MB (Zimmerberg and Gray, 1992; Johns et al., 1994; Vernotica et al., 1996; Kinsley et al., 1994). Effects on MB wane as the postpartum period progresses and there is increasing distance from the cocaine exposure (Johns et al., 2005a; Heyser et al., 1992). CC typically increases postpartum maternal aggression (MA) towards a submissive intruder by postpartum day six (PPD6) (Johns et al., 1994; Lubin et al., 2003; McMurray et al., 2008b). Conversely, AC postpartum treatment reduces MA, leaving pups defenseless during an 
intruder session (Nelson et al., 1998a; McMurray et al., 2008b). Many of the effects of cocaine treatment during or following gestation have been associated with Oxt system dysregulation in brain regions relevant to MB and MA in rats (Johns et al., 1997a; Nelson et al., 1998a; Johns et al., 1998; Vernotica et al., 1996; 1999; Lubin et al., 2003). In this review we will briefly describe the role of Oxt and its regulation associated with a number of behaviors that are disrupted by gestational cocaine treatment or exposure, and finally how intergenerational effects of cocaine including effects of prenatal exposure or rearing by a cocaine-exposed mother alters Oxt signaling.

\section{Oxytocinergic Modulation of Behavior}

\subsection{Oxytocin Signaling in Socially-Relevant Neurocircuitry}

Oxt processes from the paraventricular nucleus (PVN) and supraoptic nucleus (SON) of the hypothalamus project to the pituitary for peripheral release into the bloodstream in response to infant-produced or stressful stimuli (Wotjak et al. 1998). In the rodent, Oxt neurons from the PVN also project centrally throughout the forebrain and receptors are concentrated in the medial preoptic area (MPOA), main olfactory bulb (MOB), nucleus accumbens (NAcc), amygdala (AMY), hippocampus (HIPP), and ventral tegmental area (VTA)(Gimpl and Fahrenholz, 2001). Oxt administration or infant suckling (which substantially increases Oxt release) increases the activity of the these regions in rodents (Febo et al., 2005a), and many of these regions mediate behavioral responses relevant to maternal interactions (Numan, 2007). Similarly, clinical studies in parents have shown increased activity in the hypothalamus, VTA, striatum, and medial prefrontal cortex in response to infant auditory and visual stimuli (Strathearn, 2011).

Recently, Oxt has been proposed to modulate human brain response to infant stimuli similar to that observed in rodents. Plasma Oxt is correlated with infant-stimuli induced increases in maternal hypothalamic and striatal activity measured with functional magnetic resonance imaging (fMRI) (Strathearn et al., 2009; Strathearn, 2011). Oxt administration decreased activation in the amygdala and increased functional connectivity between the amygdala and the orbitofrontal cortex, cingulated cortex and hippocampus in nulliparous women, suggesting an important role for reducing avoidance of infant stimuli in humans (Riem et al., 2012). Interestingly, increased circulating Oxt or Oxt administration to a mother or father can enhance parental care and raise salivary Oxt in infants (Atzil et al., 2012; Weisman et al., 2012; Feldman et al., 2010). Additionally, genetic variability in the Oxt receptor and the CD38 genes have been correlated with lower plasma Oxt and reduced parental sensitivity (Feldman et al., 2012).

\subsection{Oxytocin Signaling in Parental Care and Social Behavior}

In rodents, the onset (postpartum day (PPD) 1-4) and maintenance periods (PPD 5-21) of $\mathrm{MB}$ are differentiated by their underlying hormonal state (Insel et al. 2001). Oxt and Oxt receptor expression is highly plastic during these phases (Caughey et al., 2011). Central and peripheral Oxt play a significant role in the initiation and maintenance of maternal care toward infants, which has been documented previously (Pedersen et al., 1982; 1992; Pedersen and Boccia, 2002; Ross and Young, 2009; Lee et al., 2009; Numan, 2006; Bosch and Neumann, 2011) Pedersen \& Prange 1987, Kendrick et al. 1987, Van Leengoed et al. 1987, Lee et al. 2009, Nemsadze \& Silagava 2010). Plasma Oxt is essential for milk ejection, uterine contractions and is associated with stress response (Hashimoto et al. 1989, Kalin et al. 1985, Light et al. 2004). In genetically modified mice that lack Oxt peptide or Oxt receptor, pup survival is reduced because of the loss of lactation (Young et al., 1996; Takayanagi et al., 2005). Specific deletion of the Oxt receptor in the forebrain results in increased pup mortality in the early postpartum period, suggesting a role for Oxt in the 
initiation of MB (Macbeth et al., 2010). Central levels of Oxt play a critical role in the onset of rat $\mathrm{MB}$ and are likely involved in the maintenance of $\mathrm{MB}$, the extent and direction of which is probably dependent on day of testing.

In addition to its role in parental care, Oxt has been studied extensively for its modulatory role in a variety of social behaviors in clinical and preclinical models (Lee et al., 2009; Yamasue et al., 2012; Lukas and Neumann, 2012; Kumsta and Heinrichs, 2012). Generally, greater Oxt signaling, leads to increased positive or affiliative social behaviors, and less offensive aggression. However, many recent studies have begun to more fully characterize the psychological effects and dose-response curves indicating a complex context-dependent function of Oxt in humans (Guastella et al., 2012; Feldman, 2012). Additionally, animal models have begun better define the neuroanatomical specificity for Oxt's actions (Veenema and Neumann, 2007; Ross and Young, 2009; Macbeth et al., 2010; Lee et al., 2008; Pagani et al., 2011; Dhakar et al., 2012). Specifically, a "social behavior network" including the lateral septum, extended amygdala, preoptic area, several nuclei of the hypothalamus, and the monoaminergic nuclei in the midbrain and hindbrain has been highlighted because of high Oxt receptor expression (Albers, 2012).

\subsection{Oxytocin and addiction}

Oxt has been shown to modulate the negative aspects of addiction, including reductions in acquisition, withdrawal, and relapse-like drug seeking behavior (McGregor and Bowen, 2011; McGregor et al., 2008; Sarnyai, 1999; 2011)(this issue). The complexity of the neuroanatomical and temporal effects of Oxt and interactions with other signaling systems relevant to social and addictive behaviors is still being studied (Slattery and Neumann, 2008; Yoshida et al., 2009; Yanowitch and Coccaro, 2011; Strathearn, 2011). Nonetheless, disruptions in social behavior and stress responsiveness, as well as vulnerability to drug use are increased by PCE and/or disrupted parenting. The transition into parenthood presents many novel and potentially stressful scenarios. Fortunately, Oxt, which dramatically increases during pregnancy and the postpartum period has been noted to modulate anxietylike and depressive-like behaviors across reproductive states (Lee et al., 2009; Slattery and Neumann, 2008; Viviani and Stoop, 2008; Rotzinger et al., 2010). We review the literature supporting direct effects of cocaine on Oxt in adults, primarily in females exposed during pregnancy (see Table 1), as well as the impact of maternal gestational exposure to cocaine on offspring Oxt development (Table 2).

\section{Cocaine's Effects on Adult Oxytocin Signaling in Rodents}

\subsection{Acute Cocaine Exposure}

Studies investigating the effect of cocaine exposure on Oxt regulation are summarized in Table 1. In males, acute cocaine (AC) decreases Oxt levels in the basal forebrain, but increases Oxt levels in the hypothalamus and HIPP; however these effects are dosedependent, indicating regional differences in dose-response curves (Sarnyai et al., 1992). AC exposure in a lactating female decreases Oxt levels in the MPOA but not the VTA, AMY or HIPP, on PPD 1; while increases can be seen on PPD 6 in the AMY following several intermittent AC injections. However, repeated AC decreased Oxt levels in the HIPP, hypothalamus and circulating plasma of male rats, and decreased HIPP Oxt in ovarectimized estrogen-treated females (Sarnyai et al., 1992; Johns et al., 1993). Taken together, these reports suggest hormonal state-, sex-, and treatment-specific effects of AC on Oxt signaling (Nelson et al., 1998c; Elliott et al., 2001). The underlying mechanisms controlling these sensitivities remain unknown. 


\subsection{Chronic Cocaine Exposure decreases Oxt signaling during the initiation phase of MB}

Chronic drug use often leads to substantially different neurological changes compared to acute exposures. The majority of investigations of chronic cocaine (CC) exposure on Oxt signaling have been done with pregnant rats in conjunction with studies on disrupted maternal care, with the largest effects observed in the early postpartum period. As previously noted, $\mathrm{CC}$ (20 daily treatments) treatment during pregnancy in female rats results in with lower Oxt levels in the MPOA, HIPP and VTA in the early postpartum period (postpartum day (PPD) 1-3), a time when maternal neglect occurs in the chronically treated mothers (Johns et al., 1994; 1997a; Nelson et al., 1998a; Johns et al., 2005a). Interestingly, $\mathrm{CC}$ treatment increased Oxt production in the PVN but not SON in PPD 2 rat dams, indicating a specific regional effect of CC. On PPD 5, following a pup retrieval task, CCexposed mothers had reduced plasma Oxt compared to controls, with no differences in brain Oxt in the MPOA, VTA, HIPP or nucleus accumbens (Williams et al., 2011a). However, CC-exposed mothers have higher baseline plasma levels of Oxt, and enhanced plasma Oxt response to stress (the forced swim test), but no altered HIPP or AMY responses (Williams et al., 2012). This suggests that CC-induced changes in Oxt are sensitive to behavioral context.

On PPDs 2-6, mid- and high- dose treated CC dams exhibit significantly increased threatening and attack behavior (Lubin et al., 2001a; Nelson et al., 1998b; Johns et al., 1994; 1998), and measurements of AMY Oxt levels immediately following aggression are lower in CC dams (Johns et al., 1995). An Oxt antagonist infused in the AMY, but not the VTA, of non-drug treated lactating rats also significantly increased levels of MA towards intruders on PPD 6 relative to control rats, similar to that seen in CC-treated rats strongly implicating Oxt involvement in MA behavior (Lubin et al., 2003). However, no baseline differences in Oxt levels were found on PPD 5-11 (Lubin et al., 2001a; Johns et al., 1998; Nelson et al., 1998b). Interestingly, virgin females injected with the CC regimen showed slightly decreased aggression associated with a slight decrease in HIPP Oxt levels, but no change in AMY (Lubin et al., 2001b). Taken together, these data suggest the importance of the endocrine state and time point of collection in Oxt response to CC exposure.

\subsection{Repeated Cocaine Exposure Effects Can Be Long-Lasting}

Dysregulation in baseline Oxt levels in the MPOA, VTA, AMY, and HIPP dissipates by PPD 11 (Nelson et al., 1998c) and remains stable at PPD 22 (Johns et al., 2005a). This return to typical Oxt levels in CC dams observed in the mid-lactational period is associated with reduced Oxt receptor binding in the bed nucleus of the stria terminalis and ventromedial hypothalamus but not the central nucleus of the AMY as shown with autoradiographical methods (Jarrett et al., 2006b). Additionally, higher receptor occupancy and affinity was also observed in the whole AMY at PPD 6 in rat dams (Johns et al., 2004). However, when faced with a stressful situation over 2 weeks following pup weaning, female rats exhibit decreased Oxt levels in the MPOA; this was associated with increased aggression following a competitive water task (Johns et al., 2010). Taken together, these results indicate the complexity by which cocaine can impact Oxt signaling in females across the reproductive cycle. Additionally, it highlights how drug-induced changes in stressresponsiveness can be enduring. These disruptions are brain-region-, dose-, time-, context-, and hormonal state dependent. Much more work is need to understand the intricate ways by which cocaine is altering Oxt signaling in light of how these changes can contribute negatively to maternal care during a critical developmental period for the optimal neurobehavioral welfare of the offspring. 


\subsection{Potential Monoaminergic Mechanism for Cocaine's Effects}

Mechanistic pathways underlying these cocaine-induced changes in Oxt (and perhaps neglect) have not been fully elucidated. Oxt synthesis and release and Oxt receptor regulation are modulated by a number of signaling pathways (Gimpl and Fahrenholz, 2001; McMurray et al., 2008a). As cocaine blocks reuptake of dopamine, serotonin and norepinephrine, studies looking at drugs which similarly effect these neurotransmitter systems offer insight into selective neurotransmitter involvement in drug-induced Oxt system changes and maternal care. Chronic fluoxetine (a selective serotonin reuptake inhibitor) treatment throughout pregnancy results in decreased maternal care toward pups on PPD 1, increased MA on PPD 6 and increased Oxt receptor number and affinity in the AMY, with no change in Oxt levels in MPOA, AMY or HIPP in the maintenance phase of MB (Johns et al., 2004; 2005b). When the gestational fluoxetine treatment was combined with amfonelic acid (AFA: a specific dopamine transporter blocker) decreased Oxt levels in the HIPP and increased VTA Oxt levels were observed on PPD 6 (Johns et al., 2005b). Similarly, HIPP Oxt levels were decreased when AFA was administered alone, although no increase in MA was observed. Amytryptiline, a combined norepinephrine and serotonin transporter blocker produces decreased crouching and aggression but increased licking behavior, and decreased HIPP Oxt levels on PPD 6 (Cox et al., 2011). Similarly, when the specific norepinephrine transporter blocker, desipramine, was given chronically throughout pregnancy, decreases in MB and MA along with reduced HIPP Oxt levels were observed. These data suggest that disruption in all three neurotransmitter systems or another pharmacological effect of cocaine is required to see the increased MA observed in cocaineexposed dams. However, chronic transporter inhibition disruption of dopamine or norepinephrine alone is enough to decrease basal Oxt levels in the HIPP. The effects of chronic monoamine blockade on Oxt levels during the initiation phase of MB have not yet been investigated, but we would predict lower Oxt in the MPOA given the behavioral changes observed.

\subsection{Drugs of Abuse may Generally Disrupt Maternal Care and Oxytocin}

Studies investigating changes in MB and Oxt following chronic alcohol or other drug exposure remain sparse. Acute alcohol administration studies suggest a similar impact on MB compared to cocaine (Pepino et al., 2002; Ponce et al., 2011; Pueta et al., 2008; Subramanian, 1999). In pregnant, lactating and estrous cycling women, acute alcohol reduces plasma Oxt levels (Fuchs and Fuchs, 1981; Fuchs et al., 1982; Coiro et al., 1992; Mennella et al., 2005; Mennella and Pepino, 2006). Combined gestational exposure to both chronic alcohol and chronic nicotine showed decreased MB and reduced Oxt levels in the MPOA and the VTA on PPD 1 (McMurray et al., 2008c), similar to what is observed in CC exposure. However, similar treatment did not induce changes in MA (McMurray et al., 2007). Chronic exposure studies in both animal models and clinical investigations are needed to determine whether the effects observed with cocaine exposure are similar to other drugs of abuse.

\subsection{Summary}

Exposure to drugs of abuse, in particular cocaine, during pregnancy has multiple effects on Oxt signaling that are dependent on the pharmacology, measurement taken, time of drug exposure and abstinence period, and endocrine state. A great deal more work is needed to fully understand how cocaine and other drugs of abuse impact Oxt signaling in adults. Foremost, future studies should focus on how multiple classes of drugs of abuse impact Oxt release and receptor expression in adult estrus-cycling females and further characterization of the male response should be completed. Additionally, the exact mechanism of how these various drugs are capable of disrupting Oxt remains elusive, further studies with more specific pharmacological and regional approaches can hope to answer this question. 
The current data suggest that cocaine exposure before, during or after pregnancy is altering the natural plasticity that the female brain undergoes during the transition from pregnancy to motherhood. These naturally occurring changes in neurochemistry are critical for the transition from avoidance of offspring to the complete dedication to offspring that is necessary for their survival. Hence cocaine-induced Oxt changes in brain regions associated with reward and learning (i.e. VTA, HIPP, AMY, and prefrontal cortex) and social behavior (MPOA, HIPP, and AMY), could be an underlying cause of the behavioral deficits observed. Naturally occurring changes in MPOA and VTA activity, associated with changes in Oxt levels, are important for motivation to care for pups and the transitions between MB stages \{Pereira:2011dr, Pereira:2010dp\} \{Shahrokh:2010ch\}. The observed reductions in Oxt in these regions following both AC and CC indicate that future studies should focus on how to prevent these cocaine-induced deficits or return typical functioning during the postpartum period. Similarly, the Oxt levels in the HIPP during the maintenance phase of $\mathrm{MB}$ are sensitive to many manipulations, suggesting another area of interest to study.

Alternatively, Oxt changes in the mother may be a result of altered stress-response neurocircuitry. Oxt can inhibit brain and hypothalamic-pituitary-adrenal (HPA) stress response by directly antagonizing corticotropin-releasing factor activity in the brain (Bülbül et al., 2011; Dabrowska et al., 2011; Legros, 2001). Oxt administration reduces stressinduced cortisol release in adult humans (Cardoso et al., 2012; Quirin et al., 2011) and corticosterone in male rats (Petersson et al., 1999). Additionally, Oxt signaling is associated with increased parasympathetic activity (Gamer and Büchel, 2012; McCall and Singer, 2012). This modulation of stress reactivity may be important not only for stressful social situations such as the peripartum period, but also drug response and addiction. Furthermore, addiction-related increases in anxiety and depression are thought to be partially mediated by overactive stress systems in the brain (Rotzinger et al., 2010; Logrip et al., 2011). The changes in brain and plasma Oxt following cocaine exposure suggest that other social behaviors, stress reactivity or responsiveness to drugs may be altered in chronically drug exposed females which may help explain relapse into addiction or increased postpartum mood disorders observed in these clinical populations (Williams et al., 2012; Rutherford et al., 2011).

\section{Prenatal Exposure to Cocaine and Oxytocin System Development}

\subsection{The role of Oxytocin in Development}

The multitude of effects caused by gestational cocaine exposure on the mother suggest that PCE may also alter Oxt signaling in offspring (see Table 2 for all effects). The ontogeny of Oxt signaling provides a time frame for PCE to cause a disruption. Oxt receptors can be found as early as embryonic day 14 in rats (Tribollet et al., 1989). The relevance of the activation of these receptors can be observed as early as birth with Oxt protecting the brain from excitotoxicity during birth (Khazipov et al., 2008; Ceanga et al., 2010). Additionally, Oxt during birth can have an analgesic effect on the newborns (Mazzuca et al., 2011). A single exposure to an Oxt receptor antagonist given on the fist day of life can decrease maternal-separation-induced vocalizations in female vole pups, while repeated administration increases vocalizations on postnatal day 8, indicating the dynamic develop of Oxt on infant behaviors (Kramer et al., 2003). Administration of Oxt on the day of birth also increased territorial aggression in adult females, but not males, suggesting the life-long impact of early Oxt dysregulation and a female specific vulnerability (Bales and Carter, 2003). Recent work has also implicated neonatal Oxt manipulation in the development of the serotonergic system, potentially providing a mechanism for changes in aggression (Eaton et al., 2012; Hashemi et al., 2013). These data suggest that short-term Oxt disruptions in early in life may have long-term consequences for the developing social behavior network. 
Post-weaning deletion of forebrain Oxt receptors results in reduced fear conditioning, but no changes in aggression and only minor deficits in maternal care, unlike what is observed in mice with life-long Oxt receptor deletion (Pagani et al., 2011; Macbeth et al., 2010; Dhakar et al., 2012). Chronic overstimulation of Oxt receptors during adolescence can inhibit typical social bonding in voles, however in rats with similar treatments a decrease in anxiety and ethanol consumption was observed (Bales et al., 2012; Bowen et al., 2011). The developmental time-course of Oxt receptor expression is brain-region specific and can be influenced by maternal separation (Lukas et al., 2010). Experience of a stressful childhood (abuse and neglect) results in lower plasma Oxt levels in adult men and cerebral spinal fluid levels in women, associated with higher levels depressive and anxiety scores (Opacka-Juffry and Mohiyeddini, 2012; Heim et al., 2009). These data indicate the importance of early life environment (primarily through maternal care) might alter the Oxt system and affect Oxt modulated behaviors such as aggression or drug abuse.

\subsection{Prenatal Cocaine Exposure Affects Oxytocin-Modulated Behaviors}

Prenatal exposure to drugs of abuse results in a multitude of behavioral and neurobiological changes that are still being actively investigated and the scope of which is beyond this review (see these reviews) (Glatt et al., 2000; Chae and Covington, 2009; BuckinghamHowes et al., 2013; Behnke et al., 2013). Overall many of the disruptions, particularly following PCE in rodents, and also sometimes in humans are often age, dose and sexspecific (Overstreet et al., 2000; Liu and Lester, 2011; Lambert and Bauer, 2012; Riley and LaFiette, 1996; Williams et al., 2011b; Johns and Noonan, 1995). Many of the behaviors that are altered in PCE children and rodent offspring have been shown to be modulated by Oxt signaling such as neuroendocrine stress response, agonistic and affiliative social interactions, and increased likelihood of drug abuse. Additionally, in children of women who abuse drugs during pregnancy, the risk of disruptions is enhanced. Drug abusing women are more likely to neglect their children, and child neglect has independently been shown to impact many of the same behaviors affected by prenatal exposure (Wells, 2009; Niccols et al., 2012; De Bellis, 2005; Cahill et al., 1999). This has made conclusions about the direct impact on PCE compared to early environmental stress on offspring behavior challenging. A series of preclinical cross-fostering studies was performed to better understand the contribution of prenatal exposure and an early-life environment of rearing by a drug-exposed mother. These studies often highlighted the combined exposure caused the greatest disruptions (Johns et al., 2007; 2005a; McMurray et al., 2008a; 2008b; Goodwin et al., 1992). We will review PCE-induced effects compared to those caused by being reared by a cocaine-exposed mother throughout developmental stages below.

\subsection{Infancy is a sensitive period}

In infancy, PCE toddlers showed less negative response to separation from their mothers, and differ in their response to the Still-Face task, a measure of interpreting social cues (Lewis et al., 2009; Molitor et al., 2003). These infants are often reported to be more reactive, harder to sooth and their mothers have an exaggerated response to the infant's reactivity (Schuetze et al., 2012). Similarly, in rodents, PCE infant rats are less capable of eliciting appropriate maternal care from normal rat mothers as well as CC mothers (Johns et al., 2005a), although this seems to be limited to the very early neonatal period (Heyser et al., 1992). These changes in reactivity and social responsiveness may be tied to neuroendocrine responses. Although the HPA axis is typically hypo-responsive during infancy, neonatal brain stress circuitry is responsive to maternal separation (Levine et al., 1991; Dallman, 2000). Preliminary evidence suggests that in PCE/CC reared infant rat pups on postnatal 5, there is no difference in basal or maternal separation induced plasma or brain Oxt levels; however pups at this age show lower Oxt receptor binding (Williams et al., 2010). Interestingly, PCE pups have similar Oxt receptor binding compared to controls on the day 
of birth, but have lower brain Oxt levels (Williams et al., 2010). Given the ability of small changes in Oxt signaling can have effect on other neurotransmitter systems that are known to be disrupted by PCE, such as serotonin (Williams et al., 2011b; Eaton et al., 2012), future studies are warranted to understand the exact time course of PCE effects. These data suggest that the impact of PCE may occur very early in life and can be temporally specific even, in the early neonatal period. Future studies will need to investigate the effect of PCE or rearing by a CC-exposed mother at these early time points to determine the contribution of each factor at these early stages.

\subsection{Prenatal Cocaine Affects Oxytocin-Modulated Juvenile and Adolescent Behavior}

During childhood and adolescence, continued PCE-induced deficits in stress reactivity can be seen in both clinical and preclinical studies (Williams et al., 2011b; Chae and Covington, 2009; Liu et al., 2011). Males in particular seem to be affected in both human and rodent studies, although dysregulation in behavioral stress response appears during adolescence in females with PCE. Higher anxiety-like behavior is also observed in both PCE male and female adolescent rodents (Overstreet et al., 2000). PCE is correlated with increased aggressiveness in males of both human children and young rodents (Wood and Spear, 1998; Bendersky and Lewis, 1998). PCE male and female rats spend less time interacting with conspecifics at PND 30, and they are less capable of eliciting positive social interaction from age-matched controls (Wood et al., 1995; 1994). Juvenile males were tested for pup-induced parental behavior, and those exposed to rearing by intermittently cocaine-exposed mother were less likely to perform the task to completion (Johns, 2010; Jarrett et al., 2006a); however, no changes in Oxt levels in the AMY or HIPP were in either PCE or cocainereared offspring. Since there are typical changes in regional Oxt receptor expression during childhood and adolescence, and these developmental stages are critical for learning sociallyappropriate behavior, future studies should focus on understanding how prenatal drug exposure or exposure to drug-using parents may influence Oxt signaling and behavior at these time points.

\subsection{Prenatal Cocaine Increases Aggression While Rearing by a Cocaine-Exposed Mothers Disrupts Adult Oxytocin Regulation}

The large majority of studies investigating adult rodents with PCE show increased depression and anxiety-like behaviors, and these changes have been tied to changes in HPA signaling and serotonin; however Oxt can directly modulate those systems and should be investigated in the future (Salas-Ramirez et al., 2010; Sobrian et al., 2003; Sobrian and Holson, 2011; Overstreet et al., 2000; Williams et al., 2011b). Changes in anxiety and depression are often correlated with increased aggression and PCE generally increases aggression in adult rodents. Male PCE rats showed increased aggression in water competition and resident intruder tasks (Wood and Spear, 1998; Johns, 2010; Johns and Noonan, 1995). Intermittent PCE also results in increased aggressive behavior towards an intruder male (Johns, 2010). Males with combined PCE and rearing by a CC mother show the most intense aggression in a water-competition task suggesting combined prenatal and rearing influences. Simply being reared by a CC dam was sufficient to increase aggression and reduce AMY Oxt levels in adult male rats (Jarrett et al., 2006a; Johns, 2010; Goodwin et al., 1992).

Interestingly, PCE females also exhibit increased aggression in social interactions with other females (Johns and Noonan, 1995). Both prenatal exposure and rearing by a CC-exposed mother increased MA, although the treatment schedule of cocaine exposure resulted in slightly different outcomes. Interestingly, only rearing by cocaine mother, but not PCE, reduced Oxt levels in the AMY of females on PPD 9, similar to what is observed in male water-competition aggression (McMurray et al., 2008b). These data indicate effects of 
cocaine-rearing are maintained through adulthood and major hormonal changes associated with pregnancy and lactation.

\subsection{Rearing by a Cocaine-Exposed Mothers Disrupts Adult Oxytocin Regulation and Positive Social Behaviors}

Adult rats with PCE show decreased duration of social interaction and increased avoidance with unfamiliar rats as adults (Estelles et al., 2006; Overstreet et al., 2000; Johns and Noonan, 1995). Interestingly, PCE effects on aggression and social interactions can be mediated by the housing condition of the adult offspring (Estelles et al., 2005), suggesting that the regulation of the "social neuropeptides" may be playing a role. Adult males who were reared by $\mathrm{CC}$ exposed mothers were less likely to exhibit pup-induced parental care than controls. There was no effect of PCE alone on this task indicating the importance maternal care on adult social behavior. When PCE males were reared by CC treated mothers the outcome was worse than in either situation alone with the interaction effect much more significant (Johns et al., 2007). Additionally it was observed that in the group of males reared by CC mothers that did meet the criteria, had much higher levels of Oxt in the HIPP and AMY compared to control animals that behaved similarly. This is in comparison to males reared by CC mothers that competed in the water competition task who had reduced AMY Oxt levels (Jarrett et al., 2006a; Johns, 2010). These differences could indicate different levels of resilience to the effects of PCE combined with varying levels of disrupted $\mathrm{MB}$, and that in order to typically perform social behavior an over-compensation of Oxt is needed in these offspring. Alternatively, these behavioral results suggests that perhaps Oxt receptors are down-regulated in many males reared by CC mothers, however this has not yet been empirically tested.

Female parental care was impacted by both prenatal and rearing influences. PCE disrupted pup retrieval on PPD 1, and females reared by CC-exposed mothers took longer to begin and had shorter sustained bouts of nursing (Johns et al., 2005a). Interestingly, the pattern of crouching frequency was extremely similar between females that been exposed to cocaine during pregnancy and females who had been reared by those cocaine-exposed mothers, even though they had no cocaine treatment during their own pregnancies. CC-reared females had significantly higher Oxt levels in the MPOA compared to females reared by other groups. This is similar to the increased AMY Oxt observed in CC reared males needed for pupinduced parental care, again suggesting that $\mathrm{CC}$ reared animals may need to over compensate for reductions in Oxt receptors. However, the impact of rearing by a CC exposed dam on offspring adult Oxt receptor binding has not yet been investigated.

\subsection{Rearing by a Cocaine-Exposed Mother and Vulnerability to Addiction}

PCE and cocaine rearing both result in overlapping behavioral changes in offspring; however, the molecular mechanisms underlying theses changes are not necessarily the same. These studies indicate that PCE has direct effects on the neonatal Oxt production, but does not by itself seem to cause long-term changes in adolescent or adult Oxt signaling. However, a thorough examination of all relevant brain regions in both sexes across development is needed to fully determine the long-term effects. The data support instead that rearing by a cocaine-exposed mother can have developmental, time point- and brain region- specific effects on Oxt signaling. These alterations in Oxt were tied to deficits in several social behaviors, and it is possible that other Oxt-dependent behaviors, such as drug addiction, are altered as well.

Adult mice and rats with PCE are more likely to acquire self-administration of cocaine and exhibit increased ethanol consumption (Rocha et al., 2002; Hecht et al., 1998; Kelley and Middaugh, 1996; Kelley et al., 1997). Although they will consume more drugs, PCE animals 
do not show the same learned preference for the experience, as measured by conditioned place preference (Estelles et al., 2006; Gulley et al., 1999), indicating a heightened reward threshold must be met by other drugs. Prenatal cocaine use along with parental negativity can predict cocaine use in teenagers (Delaney-Black et al., 2011). Although no studies have been performed to directly investigate the role of rearing by cocaine-exposed mothers on vulnerability to addiction, our prediction is that similar changes in Oxt signaling would occur and thus an increase in this behavioral disruption. The few studies that have investigated other drug exposure on later Oxt regulation indicate that the effect is sex and age specific, and may contribute to social behavior and drug-seeking behavior (McMurray et al., 2008c; Kelly et al., 2009; Williams et al., 2009). It is an open question whether changes have also occurred in the Oxt receptor following either PCE or cocaine-exposed mother rearing, which may find more stable changes.

\section{Conclusions}

We have focused primarily on the complex interaction of cocaine and Oxt as it relates to maternal, social and aggressive behavior with a possible role of Oxt as a mediator of some effects. It is clear that cocaine and likely other drugs of abuse can affect Oxt signaling at different time points. Oxt has a growing reputation for its role in the multiple effects of drugs abuse, which is covered in much greater detail elsewhere in this issue. Some of these effects have been tied to direct effects on dopamine signaling within the reward circuitry, potentially through direct dopamine-oxytocin receptor heteromers (Febo et al., 2005b; Qi et al., 2008; Baracz and Cornish, 2012; Kovacs et al., 1990; Love et al., 2012; Douglas, 2010; Shahrokh et al., 2010; Johns et al., 1994; Romero-Fernandez et al., 2012). Although, these interactions are likely species, sex, and age specific, so further work is necessary to fully understand these interactions.

Oxt signaling has been proposed to be one mechanism that underlies how the quality and quantity of parental care received can directly influence the type of maternal care performed in next generation rodent mothers (Pedersen and Boccia, 2002). The role of rodent maternal care in the neurodevelopment of offspring has been systematically studied, indicating that behavioral changes in the mother can produce epigenetic changes in the infant brain that in turn alter adult behavioral patterns (McGowan et al., 2011; Matthews and Phillips, 2012; Pedersen and Boccia, 2002; Champagne, 2012). Given the importance of the early dyadic relationship between mother and infant to health and well-being of both the infant and the mother, a better understanding of disruptions to this system is needed. Furthermore, changes in Oxt signaling in the mother may predispose her to relapse and drug-taking behavior; which can in turn cause longer-lasting deficits in MB creating a more tumultuous environment for her children.

Developmental changes in the Oxt system, combined with the multitude of other PCEinduced teratologies, contribute to numerous altered behavioral phenotypes including increased stress reactivity, decreased/disrupted social behavior and increased risk of drug abuse (see Figure 1). We have presented studies here that indicate that cocaine can significantly alter maternal care and various aspects of aggression intergenerationally, perhaps through cocaine's effects on the Oxt system in mothers and subsequently through altered development of the offspring's Oxt system dynamics either through prenatal exposure or rearing effects. There is the potential that Oxt plays a significant role both in drug reward circuitry and continued vulnerability to addiction in the mothers. Additionally, the multiple effects on offspring exposed to altered maternal care and drug related effects are likely mediated by epigenetic controls and can initiate a continuing cycle of intergenerational drug abuse. This highlights the need for future Oxt intervention studies 
along with continued work to discover the mechanisms by which drug abuse interacts with development and function of the Oxt system.

\section{Acknowledgments}

We would like to thank the many collaborators who contributed to the work discussed in this review. This work was financially supported by NIDA P01DA022446 (awarded to JMJ), NIDA 1R01 DA13362 (awarded to JMJ), NIDA 1R01 DA13282 (awarded to JMJ).

\section{Abbreviations}

$\begin{array}{ll}\text { PCE } & \text { prenatal cocaine exposure } \\ \text { Oxt } & \text { oxytocin } \\ \text { AC } & \text { acute cocaine } \\ \text { CC } & \text { chronic cocaine } \\ \text { MB } & \text { maternal behavior } \\ \text { MA } & \text { maternal aggression } \\ \text { PPD } & \text { postpartum day } \\ \text { MPOA } & \text { medial preoptic area } \\ \text { VTA } & \text { ventral tegmental area } \\ \text { AMY } & \text { amygdala } \\ \text { HIPP } & \text { hippocampus } \\ \text { PVN } & \text { paraventricular nucleus } \\ \text { SON } & \text { supraoptic nucleus } \\ \text { AFA } & \text { amfonelic acid } \\ \text { HPA } & \text { hypothalamic-pituitary-adrenal }\end{array}$

\section{References}

Albers HE. The regulation of social recognition, social communication and aggression: vasopressin in the social behavior neural network. Horm Behav. 2012; 61:283-292. [PubMed: 22079778]

Atzil S, Hendler T, Zagoory-Sharon O, Winetraub Y, Feldman R. Synchrony and specificity in the maternal and the paternal brain: relations to oxytocin and vasopressin. J Am Acad Child Adolesc Psychiatry. 2012; 51:798-811. [PubMed: 22840551]

Bales KL, Carter CS. Sex differences and developmental effects of oxytocin on aggression and social behavior in prairie voles (Microtus ochrogaster). Horm Behav. 2003; 44:178-184. [PubMed: 14609540]

Bales KL, Perkeybile AM, Conley OG, Lee MH, Guoynes CD, Downing GM, Yun CR, Solomon M, Jacob S, Mendoza SP. Chronic Intranasal Oxytocin Causes Long-Term Impairments in Partner Preference Formation in Male Prairie Voles. Biol Psychiatry. 2012

Baracz SJ, Cornish JL. Oxytocin modulates dopamine-mediated reward in the rat subthalamic nucleus. Horm Behav. 2012

Behnke M, Smith VC. Committee on Substance Abuse Committee on Fetus and Newborn. Prenatal substance abuse: short- and long-term effects on the exposed fetus. Pediatrics. 2013; 131:e1009-24. [PubMed: 23439891]

Bendersky M, Lewis M. Prenatal cocaine exposure and impulse control at two years. Ann N Y Acad Sci. 1998; 846:365-367. [PubMed: 9668426] 
Black MM, Nair P, Kight C, Wachtel R, Roby P, Schuler M. Parenting and early development among children of drug-abusing women: effects of home intervention. Pediatrics. 1994; 94:440-448. [PubMed: 7936850]

Bosch OJ, Neumann ID. Both oxytocin and vasopressin are mediators of maternal care and aggression in rodents: From central release to sites of action. Horm Behav. 2011

Bowen MT, Carson DS, Spiro A, Arnold JC, McGregor IS. Adolescent oxytocin exposure causes persistent reductions in anxiety and alcohol consumption and enhances sociability in rats. PLoS ONE. 2011; 6:e27237. [PubMed: 22110618]

Buckingham-Howes S, Berger SS, Scaletti LA, Black MM. Systematic review of prenatal cocaine exposure and adolescent development. Pediatrics. 2013; 131:e1917-36. [PubMed: 23713107]

Burns K, Chethik L, Burns WJ, Clark R. Dyadic disturbances in cocaine-abusing mothers and their infants. J Clin Psychol. 1991; 47:316-319. [PubMed: 2030140]

Bülbül M, Babygirija R, Cerjak D, Yoshimoto S, Ludwig K, Takahashi T. Hypothalamic oxytocin attenuates CRF expression via GABA(A) receptors in rats. Brain Res. 2011; 1387:39-45. [PubMed: 21382355]

Cahill LT, Kaminer RK, Johnson PG. Developmental, cognitive, and behavioral sequelae of child abuse. Child Adolesc Psychiatr Clin N Am. 1999; 8:827-43. ix-x. [PubMed: 10553206]

Cardoso C, Ellenbogen MA, Orlando MA, Bacon SL, Joober R. Intranasal oxytocin attenuates the cortisol response to physical stress: A dose-response study. Psychoneuroendocrinology. 2012

Caughey SD, Klampfl SM, Bishop VR, Pfoertsch J, Neumann ID, Bosch OJ, Meddle SL. Changes in the intensity of maternal aggression and central oxytocin and vasopressin V1a receptors across the peripartum period in the rat. J Neuroendocrinol. 2011; 23:1113-1124. [PubMed: 21929717]

Ceanga M, Spataru A, Zagrean AM. Oxytocin is neuroprotective against oxygen-glucose deprivation and reoxygenation in immature hippocampal cultures. Neurosci Lett. 2010; 477:15-18. [PubMed: 20399835]

Chae SM, Covington CY. Biobehavioral outcomes in adolescents and young adults prenatally exposed to cocaine: evidence from animal models. Biol Res Nurs. 2009; 10:318-330. [PubMed: 19141484]

Champagne FA. Interplay between social experiences and the genome: epigenetic consequences for behavior. Adv Genet. 2012; 77:33-57. [PubMed: 22902125]

Coiro V, Alboni A, Gramellini D, Cigarini C, Bianconi L, Pignatti D, Volpi R, Chiodera P. Inhibition by ethanol of the oxytocin response to breast stimulation in normal women and the role of endogenous opioids. Acta Endocrinol. 1992; 126:213-216. [PubMed: 1574949]

Cox ET, Jarrett TM, McMurray MS, Greenhill K, Hofler VE, Williams SK, Joyner PW, Middleton CL, Walker CH, Johns JM. Combined norepinephrine/serotonergic reuptake inhibition: effects on maternal behavior, aggression, and oxytocin in the rat. Front Psychiatry. 2011; 2:34. [PubMed: 21713063]

Dabrowska J, Hazra R, Ahern TH, Guo JD, McDonald AJ, Mascagni F, Muller JF, Young LJ, Rainnie DG. Neuroanatomical evidence for reciprocal regulation of the corticotrophin-releasing factor and oxytocin systems in the hypothalamus and the bed nucleus of the stria terminalis of the rat: Implications for balancing stress and affect. Psychoneuroendocrinology. 2011; 36:1312-1326. [PubMed: 21481539]

Dallman MF. Moments in time--the neonatal rat hypothalamo-pituitary-adrenal axis. Endocrinology. 2000; 141:1590-1592. [PubMed: 10803565]

De Bellis MD. The psychobiology of neglect. Child Maltreat. 2005; 10:150-172. [PubMed: 15798010]

Delaney-Black V, Chiodo LM, Hannigan JH, Greenwald MK, Janisse J, Patterson G, Huestis MA, Partridge RT, Ager J, Sokol RJ. Prenatal and postnatal cocaine exposure predict teen cocaine use. Neurotoxicol Teratol. 2011; 33:110-119. [PubMed: 20609384]

Dhakar MB, Rich ME, Reno EL, Lee HJ, Caldwell HK. Heightened aggressive behavior in mice with lifelong versus postweaning knockout of the oxytocin receptor. Horm Behav. 2012; 62:86-92. [PubMed: 22609339]

Douglas AJ. Baby love? Oxytocin-dopamine interactions in mother-infant bonding. Endocrinology. 2010; 151:1978-1980. [PubMed: 20410209]

Dow-Edwards D. Translational issues for prenatal cocaine studies and the role of environment. Neurotoxicol Teratol. 2011; 33:9-16. [PubMed: 20600842] 
Eaton JL, Roache L, Nguyen KN, Cushing BS, Troyer E, Papademetriou E, Raghanti MA. Organizational effects of oxytocin on serotonin innervation. Dev Psychobiol. 2012; 54:92-97. [PubMed: 21594870]

Eiden RD, Foote A, Schuetze P. Maternal cocaine use and caregiving status: group differences in caregiver and infant risk variables. Addict Behav. 2007; 32:465-476. [PubMed: 16837139]

Eiden RD, Stevens A, Schuetze P, Dombkowski LE. Conceptual model for maternal behavior among polydrug cocaine-using mothers: the role of postnatal cocaine use and maternal depression. Psychol Addict Behav. 2006; 20:1-10. [PubMed: 16536660]

Elliott JC, Lubin DA, Walker CH, Johns JM. Acute cocaine alters oxytocin levels in the medial preoptic area and amygdala in lactating rat dams: implications for cocaine-induced changes in maternal behavior and maternal aggression. Neuropeptides. 2001; 35:127-134. [PubMed: 11384208]

Estelles J, Rodríguez-Arias M, Maldonado C, Aguilar MA, Miñarro J. Prenatal cocaine exposure alters spontaneous and cocaine-induced motor and social behaviors. Neurotoxicol Teratol. 2005; 27:449-457. [PubMed: 15939204]

Estelles J, Rodríguez-Arias M, Maldonado C, Manzanedo C, Aguilar MA, Miñarro J. Prenatal cocaine alters later responses to morphine in adult male mice. Prog Neuropsychopharmacol Biol Psychiatry. 2006; 30:1073-1082. [PubMed: 16737762]

Febo M, Numan M, Ferris CF. Functional magnetic resonance imaging shows oxytocin activates brain regions associated with mother-pup bonding during suckling. J Neurosci. 2005a; 25:11637-11644. [PubMed: 16354922]

Febo M, Segarra AC, Nair G, Schmidt K, Duong TQ, Ferris CF. The neural consequences of repeated cocaine exposure revealed by functional MRI in awake rats. Neuropsychopharmacology. 2005b; 30:936-943. [PubMed: 15637636]

Feldman R. Oxytocin and social affiliation in humans. Horm Behav. 2012; 61:380-391. [PubMed: 22285934]

Feldman R, Gordon I, Schneiderman I, Weisman O, Zagoory-Sharon O. Natural variations in maternal and paternal care are associated with systematic changes in oxytocin following parent-infant contact. Psychoneuroendocrinology. 2010; 35:1133-1141. [PubMed: 20153585]

Feldman R, Zagoory-Sharon O, Weisman O, Schneiderman I, Gordon I, Maoz R, Shalev I, Ebstein RP. Sensitive parenting is associated with plasma oxytocin and polymorphisms in the OXTR and CD38 genes. Biol Psychiatry. 2012; 72:175-181. [PubMed: 22336563]

Fuchs AR, Fuchs F. Ethanol for prevention of preterm birth. Semin Perinatol. 1981; 5:236-251. [PubMed: 7025216]

Fuchs AR, Husslein P, Sumulong L, Micha JP, Dawood MY, Fuchs F. Plasma levels of oxytocin and 13, 14-dihydro-15-keto prostaglandin F2 alpha in preterm labor and the effect of ethanol and ritodrine. Am J Obstet Gynecol. 1982; 144:753-759. [PubMed: 7148897]

Gamer M, Büchel C. Oxytocin specifically enhances valence-dependent parasympathetic responses. Psychoneuroendocrinology. 2012; 37:87-93. [PubMed: 21641726]

Gimpl G, Fahrenholz F. The oxytocin receptor system: structure, function, and regulation. Physiol Rev. 2001; 81:629-683. [PubMed: 11274341]

Glatt SJ, Bolaños CA, Trksak GH, Crowder-Dupont C, Jackson D. Prenatal cocaine exposure alters behavioral and neurochemical sensitization to amphetamine in adult rats. Neuropharmacology. 2000; 39:599-610. [PubMed: 10728881]

Goodwin GA, Heyser CJ, Moody CA, Rajachandran L, Molina VA, Arnold HM, McKinzie DL, Spear NE, Spear LP. A fostering study of the effects of prenatal cocaine exposure: II. Offspring behavioral measures. Neurotoxicol Teratol. 1992; 14:423-432. [PubMed: 1488037]

Guastella AJ, Graustella AJ, MacLeod C. A critical review of the influence of oxytocin nasal spray on social cognition in humans: evidence and future directions. Horm Behav. 2012; 61:410-418. [PubMed: 22265852]

Gulley JM, Billman SP, Gilliam DM, George FR. Operant-self-administration of ethanol in mice prenatally exposed to cocaine. J Addict Dis. 1999; 18:77-89. [PubMed: 10507584] 
Hashemi F, Tekes K, Laufer R, Szegi P, Tóthfalusi L, Csaba G. Effect of a Single Neonatal Oxytocin Treatment (Hormonal Imprinting) on the Biogenic Amine Level of the Adult Rat Brain: Could Oxytocin-Induced Labor Cause Pervasive Developmental Diseases? Reprod Sci. 2013

Hecht GS, Spear NE, Spear LP. Alterations in the reinforcing efficacy of cocaine in adult rats following prenatal exposure to cocaine. Behav Neurosci. 1998; 112:410-418. [PubMed: 9588487]

Heim C, Young LJ, Newport DJ, Mletzko T, Miller AH, Nemeroff CB. Lower CSF oxytocin concentrations in women with a history of childhood abuse. Mol Psychiatry. 2009; 14:954-958. [PubMed: 18957940]

Heyser CJ, Molina VA, Spear LP. A fostering study of the effects of prenatal cocaine exposure: I. Maternal behaviors. Neurotoxicol Teratol. 1992; 14:415-421. [PubMed: 1488036]

Jarrett, TM.; McMurray, MS.; Johns, JM.; Walker, CH. Effects of Prenatal Cocaine Exposure and Rearing Condition on Social/Aggressive Behavior and Oxytocin Levels in Young Adult Male Rats on a Water Competition Task. Whistler: Proceedings of the International Behavioral Neuroscience Society; 2006a.

Jarrett TM, McMurray MS, Walker CH, Johns JM. Cocaine treatment alters oxytocin receptor binding but not mRNA production in postpartum rat dams. Neuropeptides. 2006b; 40:161-167. [PubMed: 16677710]

Johns, JM. Cocaine's effects on mother and infant phenotypes: Models of intergenerational and translational mechanisms which may impact offspring vulnerability. Sardinia: Proceedings of the International Behavioral Neuroscience Society; 2010.

Johns JM, Noonan LR. Prenatal cocaine exposure affects social behavior in Sprague-Dawley rats. Neurotoxicol Teratol. 1995; 17:569-576. [PubMed: 8552003]

Johns JM, Caldwell JD, Pedersen CA. Acute cocaine treatment decreases oxytocin levels in the rat hippocampus. Neuropeptides. 1993; 24:165-169. [PubMed: 8474635]

Johns JM, Elliott DL, Hofler VE, Joyner PW, McMurray MS, Jarrett TM, Haslup AM, Middleton CL, Elliott JC, Walker $\mathrm{CH}$. Cocaine treatment and prenatal environment interact to disrupt intergenerational maternal behavior in rats. Behav Neurosci. 2005a; 119:1605-1618. [PubMed: 16420163]

Johns, JM.; Faggin, BM.; Noonan, LR.; Li, L.; Zimmerman, LI.; Pedersen, CA. Chronic cocaine treatment decreases oxytocin levels in the amygdala and increases maternal aggression in SpragueDawley rats. 1995.

Johns JM, Joyner PW, McMurray MS, Elliott DL, Hofler VE, Middleton CL, Knupp K, Greenhill $\mathrm{KW}$, Lomas LM, Walker CH. The effects of dopaminergic/serotonergic reuptake inhibition on maternal behavior, maternal aggression, and oxytocin in the rat. Pharmacol Biochem Behav. 2005b; 81:769-785. [PubMed: 15996723]

Johns JM, Lubin DA, Walker CH, Joyner P, Middleton C, Hofler V, McMurray M. Gestational treatment with cocaine and fluoxetine alters oxytocin receptor number and binding affinity in lactating rat dams. Int J Dev Neurosci. 2004; 22:321-328. [PubMed: 15380831]

Johns JM, Lubin DA, Walker CH, Meter KE, Mason GA. Chronic gestational cocaine treatment decreases oxytocin levels in the medial preoptic area, ventral tegmental area and hippocampus in Sprague-Dawley rats. Neuropeptides. 1997a

Johns JM, McMurray MS, Hofler VE, Jarrett TM, Middleton CL, Elliott DL, Mirza R, Haslup A, Elliott JC, Walker CH. Cocaine disrupts pup-induced maternal behavior in juvenile and adult rats. Neurotoxicol Teratol. 2007; 29:634-641. [PubMed: 17698321]

Johns JM, McMurray MS, Joyner PW, Jarrett TM, Williams SK, Cox ET, Black MA, Middleton CL, Walker $\mathrm{CH}$. Effects of chronic and intermittent cocaine treatment on dominance, aggression, and oxytocin levels in post-lactational rats. Psychopharmacology (Berl). 2010; 211:175-185. [PubMed: 20526586]

Johns JM, Noonan LR, Zimmerman LI, Li L, Pedersen CA. Effects of chronic and acute cocaine treatment on the onset of maternal behavior and aggression in Sprague-Dawley rats. Behav Neurosci. 1994; 108:107-112. [PubMed: 8192835]

Johns JM, Noonan LR, Zimmerman LI, Li L, Pedersen CA. Effects of Short- and Long-Term Withdrawal from Gestational Cocaine Treatment on Maternal Behavior and Aggression in Sprague-Dawley Rats. Dev Neurosci. 1997b; 19:368-374. [PubMed: 9215883] 
Johns JM, Noonan LR, Zimmerman LI, McMillen BA, Means LW, Walker CH, Lubin DA, Meter KE, Nelson CJ, Pedersen CA, et al. Chronic cocaine treatment alters social/aggressive behavior in Sprague-Dawley rat dams and in their prenatally exposed offspring. Ann N Y Acad Sci. 1998; 846:399-404. [PubMed: 9668435]

Johnson AL, Morrow CE, Accornero VH, Xue L, Anthony JC, Bandstra ES. Maternal cocaine use: estimated effects on mother-child play interactions in the preschool period. J Dev Behav Pediatr. 2002; 23:191-202. [PubMed: 12177564]

Kelley BM, Middaugh LD. Ethanol self-administration and motor deficits in adults C57BL/6J mice exposed prenatally to cocaine. Pharmacol Biochem Behav. 1996; 55:575-584. [PubMed: 8981588]

Kelley BM, Groseclose CH, Middaugh LD. Prenatal cocaine exposure increases the reinforcing strength of oral ethanol in C57 mice. Neurotoxicol Teratol. 1997; 19:391-398. [PubMed: 9380006]

Kelly SJ, Leggett DC, Cronise K. Sexually dimorphic effects of alcohol exposure during development on the processing of social cues. Alcohol Alcohol. 2009; 44:555-560. [PubMed: 19767624]

Khazipov R, Tyzio R, Ben-Ari Y. Effects of oxytocin on GABA signalling in the foetal brain during delivery. Prog Brain Res. 2008; 170:243-257. [PubMed: 18655887]

Kinsley CH, Turco D, Bauer A, Beverly M, Wellman J, Graham AL. Cocaine alters the onset and maintenance of maternal behavior in lactating rats. Pharmacol Biochem Behav. 1994; 47:857-864. [PubMed: 8029256]

Kovacs GL, Sarnyai Z, Babarczi E, Szabo G, Telegdy G. The role of oxytocin-dopamine interactions in cocaine-induced locomotor hyperactivity. Neuropharmacology. 1990; 29:365-368. [PubMed: 2160623]

Kramer KM, Cushing BS, Carter CS. Developmental effects of oxytocin on stress response: single versus repeated exposure. Physiol Behav. 2003; 79:775-782. [PubMed: 12954422]

Kumsta R, Heinrichs M. Oxytocin, stress and social behavior: neurogenetics of the human oxytocin system. Curr Opin Neurobiol. 2012

Lambert BL, Bauer CR. Developmental and behavioral consequences of prenatal cocaine exposure: a review. J Perinatol. 2012; 32:819-828. [PubMed: 22791278]

Lee HJ, Caldwell HK, Macbeth AH, Young WS. Behavioural studies using temporal and spatial inactivation of the oxytocin receptor. Prog Brain Res. 2008; 170:73-77. [PubMed: 18655873]

Lee HJ, Macbeth AH, Pagani JH, Young WS. Oxytocin: the great facilitator of life. Prog Neurobiol. 2009; 88:127-151. [PubMed: 19482229]

Legros JJ. Inhibitory effect of oxytocin on corticotrope function in humans: are vasopressin and oxytocin ying-yang neurohormones? Psychoneuroendocrinology. 2001; 26:649-655. [PubMed: 11500247]

Lester BM, Padbury JF. Third pathophysiology of prenatal cocaine exposure. Dev Neurosci. 2009; 31:23-35. [PubMed: 19372684]

Lester BM, LaGasse LL, Seifer R. Cocaine exposure and children: the meaning of subtle effects. Science. 1998; 282:633-634. [PubMed: 9841414]

Levine S, Huchton DM, Wiener SG, Rosenfeld P. Time course of the effect of maternal deprivation on the hypothalamic-pituitary-adrenal axis in the infant rat. Dev Psychobiol. 1991; 24:547-558. [PubMed: 1773913]

Lewis MW, Phillips G, Bowser M, DeLuca S, Johnson HL, Rosen TS. Cocaine-exposed infant behavior during Still-Face: risk factor analyses. Am J Orthopsychiatry. 2009; 79:60-70. [PubMed: 19290726]

Light KC, Grewen KM, Amico JA, Boccia M, Brownley KA, Johns JM. Deficits in plasma oxytocin responses and increased negative affect, stress, and blood pressure in mothers with cocaine exposure during pregnancy. Addict Behav. 2004; 29:1541-1564. [PubMed: 15451123]

Liu J, Lester BM. Reconceptualizing in a dual-system model the effects of prenatal cocaine exposure on adolescent development: a short review. Int J Dev Neurosci. 2011; 29:803-809. [PubMed: 21946244] 
Liu J, Cohen RA, Gongvatana A, Sheinkopf SJ, Lester BM. Impact of prenatal exposure to cocaine and tobacco on diffusion tensor imaging and sensation seeking in adolescents. J Pediatr. 2011; 159:771-775. [PubMed: 21723565]

Logrip ML, Koob GF, Zorrilla EP. Role of corticotropin-releasing factor in drug addiction: potential for pharmacological intervention. CNS Drugs. 2011; 25:271-287. [PubMed: 21425881]

Love TM, Enoch MA, Hodgkinson CA, Peciña M, Mickey B, Koeppe RA, Stohler CS, Goldman D, Zubieta JK. Oxytocin gene polymorphisms influence human dopaminergic function in a sexdependent manner. Biol Psychiatry. 2012; 72:198-206. [PubMed: 22418012]

Lubin DA, Elliott JC, Black MC, Johns JM. An oxytocin antagonist infused into the central nucleus of the amygdala increases maternal aggressive behavior. Behav Neurosci. 2003; 117:195-201. [PubMed: 12708515]

Lubin DA, Meter KE, Walker CH, Johns JM. Dose-related effects of chronic gestational cocaine treatment on maternal aggression in rats on postpartum days 2, 3, and 5. Prog Neuropsychopharmacol Biol Psychiatry. 2001a; 25:1403-1420. [PubMed: 11513355]

Lubin DA, Meter KE, Walker CH, Johns JM. Effects of chronic cocaine administration on aggressive behavior in virgin rats. Prog Neuropsychopharmacol Biol Psychiatry. 2001b; 25:1421-1433. [PubMed: 11513356]

Lukas M, Neumann ID. Oxytocin and vasopressin in rodent behaviors related to social dysfunctions in autism spectrum disorders. Behav Brain Res. 2012

Lukas M, Bredewold R, Neumann ID, Veenema AH. Maternal separation interferes with developmental changes in brain vasopressin and oxytocin receptor binding in male rats. Neuropharmacology. 2010; 58:78-87. [PubMed: 19560475]

Macbeth AH, Stepp JE, Lee HJ, Young WS, Caldwell HK. Normal maternal behavior, but increased pup mortality, in conditional oxytocin receptor knockout females. Behav Neurosci. 2010; 124:677-685. [PubMed: 20939667]

Matthews SG, Phillips DI. Transgenerational inheritance of stress pathology. Exp Neurol. 2012; 233:95-101. [PubMed: 21281632]

Mazzuca M, Minlebaev M, Shakirzyanova A, Tyzio R, Taccola G, Janackova S, Gataullina S, Ben-Ari Y, Giniatullin R, Khazipov R. Newborn Analgesia Mediated by Oxytocin during Delivery. Front Cell Neurosci. 2011; 5:3. [PubMed: 21519396]

McCall C, Singer T. The animal and human neuroendocrinology of social cognition, motivation and behavior. Nat Neurosci. 2012; 15:681-688. [PubMed: 22504348]

McGowan PO, Suderman M, Sasaki A, Huang TCT, Hallett M, Meaney MJ, Szyf M. Broad epigenetic signature of maternal care in the brain of adult rats. PLoS ONE. 2011; 6:e14739. [PubMed: 21386994]

McGregor IS, Bowen MT. Breaking the loop: Oxytocin as a potential treatment for drug addiction. Horm Behav. 2011

McGregor IS, Callaghan PD, Hunt GE. From ultrasocial to antisocial: a role for oxytocin in the acute reinforcing effects and long-term adverse consequences of drug use? Br J Pharmacol. 2008; 154:358-368. [PubMed: 18475254]

McMurray MS, Cox ET, Jarrett TM, Williams SK, Walker CH, Johns JM. Impact of gestational cocaine treatment or prenatal cocaine exposure on early postpartum oxytocin mRNA levels and receptor binding in the rat. Neuropeptides. 2008a; 42:641-652. [PubMed: 18579201]

McMurray MS, Joyner PW, Middleton CW, Jarrett TM, Elliott DL, Black MA, Hofler VE, Walker $\mathrm{CH}$, Johns JM. Intergenerational effects of cocaine on maternal aggressive behavior and brain oxytocin in rat dams. Stress. 2008b; 11:398-410. [PubMed: 18609307]

McMurray MS, Williams SK, Jarrett TM, Cox ET, Fay EE, Overstreet DH, Walker CH, Johns JM. Gestational ethanol and nicotine exposure: effects on maternal behavior, oxytocin, and offspring ethanol intake in the rat. Neurotoxicol Teratol. 2008c; 30:475-486. [PubMed: 18664381]

McMurray MS, Williams SK, Jarrett TM, Fay EE, Overstreet DH, Walker CH, Johns JM. Effect of gestational alcohol and nicotine treatment on postpartum maternal behavior and maternal aggression. Research Society for Alcoholism. 2007

Mennella JA, Pepino MY. Short-term effects of alcohol consumption on the hormonal milieu and mood states in nulliparous women. Alcohol. 2006; 38:29-36. [PubMed: 16762689] 
Mennella JA, Pepino MY, Teff KL. Acute alcohol consumption disrupts the hormonal milieu of lactating women. J Clin Endocrinol Metab. 2005; 90:1979-1985. [PubMed: 15623810]

Minnes S, Singer LT, Arendt R, Satayathum S. Effects of prenatal cocaine/polydrug use on maternalinfant feeding interactions during the first year of life. J Dev Behav Pediatr. 2005; 26:194-200. [PubMed: 15956868]

Molitor A, Mayes LC, Ward A. Emotion regulation behavior during a separation procedure in 18month-old children of mothers using cocaine and other drugs. Dev Psychopathol. 2003; 15:3954. [PubMed: 12848434]

Nelson CJ, Meter KE, Lubin DA, Couch D, Ayers AA, Walker CH, Johns JM. Dose-Dependent Effects of Multiple Acute Cocaine Injections on Maternal Behavior and Aggression in SpragueDawley Rats. Dev Neurosci. 1998a; 20:525. [PubMed: 9858841]

Nelson CJ, Meter KE, Walker CH, Ayers AA. A dose response study of chronic cocaine on maternal behavior in rats. Neurotoxicology and .... 1998b

Nelson CJ, Meter KE, Walker CH, Ayers AA, Johns JM. A dose-response study of chronic cocaine on maternal behavior in rats. Neurotoxicol Teratol. 1998c; 20:657-660. [PubMed: 9831128]

Nephew BC, Febo M. Effects of cocaine on maternal behavior and neurochemistry. Curr Neuropharmacol. 2012; 10:53-63. [PubMed: 22942878]

Niccols A, Milligan K, Sword W, Thabane L, Henderson J, Smith A. Integrated programs for mothers with substance abuse issues: A systematic review of studies reporting on parenting outcomes. Harm Reduct J. 2012; 9:14. [PubMed: 22429792]

Numan M. Hypothalamic neural circuits regulating maternal responsiveness toward infants. Behav Cogn Neurosci Rev. 2006; 5:163-190. [PubMed: 17099111]

Numan M. Motivational systems and the neural circuitry of maternal behavior in the rat. Dev Psychobiol. 2007; 49:12-21. [PubMed: 17186513]

Opacka-Juffry J, Mohiyeddini C. Experience of stress in childhood negatively correlates with plasma oxytocin concentration in adult men. Stress. 2012; 15:1-10. [PubMed: 21682649]

Overstreet DH, Moy SS, Lubin DA, Gause LR, Lieberman JA, Johns JM. Enduring effects of prenatal cocaine administration on emotional behavior in rats. Physiol Behav. 2000; 70:149-156. [PubMed: 10978490]

Pagani JH, Lee HJ, Young WS. Postweaning, forebrain-specific perturbation of the oxytocin system impairs fear conditioning. Genes Brain Behav. 2011; 10:710-719. [PubMed: 21668734]

Pedersen CA, Boccia ML. Oxytocin links mothering received, mothering bestowed and adult stress responses. Stress. 2002; 5:259-267. [PubMed: 12475730]

Pedersen CA, Ascher JA, Monroe YL, Prange AJ. Oxytocin induces maternal behavior in virgin female rats. Science. 1982; 216:648-650. [PubMed: 7071605]

Pedersen CA, Caldwell JD, Peterson G, Walker CH, Mason GA. Oxytocin activation of maternal behavior in the rat. Ann N Y Acad Sci. 1992; 652:58-69. [PubMed: 1626858]

Pepino MY, Abate P, Spear NE, Molina JC. Disruption of maternal behavior by alcohol intoxication in the lactating rat: a behavioral and metabolic analysis. Alcohol Clin Exp Res. 2002; 26:12051214. [PubMed: 12198395]

Petersson M, Hulting AL, Uvnäs-Moberg K. Oxytocin causes a sustained decrease in plasma levels of corticosterone in rats. Neurosci Lett. 1999; 264:41-44. [PubMed: 10320009]

Ponce LF, Pautassi RM, Spear NE, Molina JC. Maternal care alterations induced by repeated ethanol leads to heightened consumption of the drug and motor impairment during adolescence: a doseresponse analysis. Physiol Behav. 2011; 103:477-486. [PubMed: 21334354]

Pueta M, Abate P, Haymal OB, Spear NE, Molina JC. Ethanol exposure during late gestation and nursing in the rat: effects upon maternal care, ethanol metabolism and infantile milk intake. Pharmacol Biochem Behav. 2008; 91:21-31. [PubMed: 18602418]

Qi J, Yang JY, Song M, Li Y, Wang F, Wu CF. Inhibition by oxytocin of methamphetamine-induced hyperactivity related to dopamine turnover in the mesolimbic region in mice. Naunyn Schmiedebergs Arch Pharmacol. 2008; 376:441-448. [PubMed: 18092152]

Quirin M, Kuhl J, Düsing R. Oxytocin buffers cortisol responses to stress in individuals with impaired emotion regulation abilities. Psychoneuroendocrinology. 2011; 36:898-904. [PubMed: 21208748] 
Riem MME, van IJzendoorn MH, Tops M, Boksem MAS, Rombouts SARB, Bakermans-Kranenburg MJ. No laughing matter: intranasal oxytocin administration changes functional brain connectivity during exposure to infant laughter. Neuropsychopharmacology. 2012; 37:1257-1266. [PubMed: 22189289]

Riley EP, LaFiette MH. The effects of prenatal cocaine exposure on subsequent learning in the rat. NIDA Res Monogr. 1996; 164:53-77. [PubMed: 8809868]

Rocha BA, Mead AN, Kosofsky BE. Increased vulnerability to self-administer cocaine in mice prenatally exposed to cocaine. Psychopharmacology (Berl). 2002; 163:221-229. [PubMed: 12202969]

Romero-Fernandez W, Borroto-Escuela DO, Agnati LF, Fuxe K. Evidence for the existence of dopamine $\mathrm{d} 2$-oxytocin receptor heteromers in the ventral and dorsal striatum with facilitatory receptor-receptor interactions. Mol Psychiatry. 2012

Ross HE, Young LJ. Oxytocin and the neural mechanisms regulating social cognition and affiliative behavior. Front Neuroendocrinol. 2009; 30:534-547. [PubMed: 19481567]

Rotzinger S, Lovejoy DA, Tan LA. Behavioral effects of neuropeptides in rodent models of depression and anxiety. Peptides. 2010; 31:736-756. [PubMed: 20026211]

Rutherford HJV, Williams SK, Moy S, Mayes LC, Johns JM. Disruption of maternal parenting circuitry by addictive process: rewiring of reward and stress systems. Front Psychiatry. 2011; 2:37. [PubMed: 21779252]

Salas-Ramirez KY, Frankfurt M, Alexander A, Luine VN, Friedman E. Prenatal cocaine exposure increases anxiety, impairs cognitive function and increases dendritic spine density in adult rats: influence of sex. Neuroscience. 2010; 169:1287-1295. [PubMed: 20553818]

Sarnyai Z. Oxytocin and neuroadaptation to cocaine. Prog Brain Res. 1999

Sarnyai Z. Oxytocin as a potential mediator and modulator of drug addiction. Addict Biol. 2011; 16:199-201. [PubMed: 21371175]

Sarnyai Z, Vecsernyés M, Laczi F, Bíró É, Szabo G, Kovacs GL. Effects of cocaine on the contents of neurohypophyseal hormones in the plasma and in different brain structures in rats. Neuropeptides. 1992; 23:27-31. [PubMed: 1407414]

Schuetze P, Molnar DS, Eiden RD. Profiles of Reactivity in Cocaine-Exposed Children. J Appl Dev Psychol. 2012; 33:282-293. [PubMed: 23204615]

Shahrokh DK, Zhang TY, Diorio J, Gratton A, Meaney MJ. Oxytocin-dopamine interactions mediate variations in maternal behavior in the rat. Endocrinology. 2010; 151:2276-2286. [PubMed: 20228171]

Slattery DA, Neumann ID. No stress please! Mechanisms of stress hyporesponsiveness of the maternal brain. J Physiol (Lond). 2008; 586:377-385. [PubMed: 17974588]

Sobrian SK, Holson RR. Social behavior of offspring following prenatal cocaine exposure in rodents: a comparison with prenatal alcohol. Front Psychiatry. 2011; 2:66. [PubMed: 22144967]

Sobrian SK, Marr L, Ressman K. Prenatal cocaine and/or nicotine exposure produces depression and anxiety in aging rats. Prog Neuropsychopharmacol Biol Psychiatry. 2003; 27:501-518. [PubMed: 12691787]

Solis JM, Shadur JM, Burns AR, Hussong AM. Understanding the diverse needs of children whose parents abuse substances. Curr Drug Abuse Rev. 2012; 5:135-147. [PubMed: 22455509]

Strathearn L. Maternal neglect: oxytocin, dopamine and the neurobiology of attachment. J Neuroendocrinol. 2011; 23:1054-1065. [PubMed: 21951160]

Strathearn L, Mayes LC. Cocaine addiction in mothers: potential effects on maternal care and infant development. Ann N Y Acad Sci. 2010; 1187:172-183. [PubMed: 20201853]

Strathearn L, Fonagy P, Amico J, Montague PR. Adult attachment predicts maternal brain and oxytocin response to infant cues. Neuropsychopharmacology. 2009; 34:2655-2666. [PubMed: 19710635]

Subramanian MG. Alcohol inhibits suckling-induced oxytocin release in the lactating rat. Alcohol. 1999; 19:51-55. [PubMed: 10487388]

Suchman NE, DeCoste C, Castiglioni N, McMahon TJ, Rounsaville B, Mayes L. The Mothers and Toddlers Program, an attachment-based parenting intervention for substance using women: post- 
treatment results from a randomized clinical pilot. Attach Hum Dev. 2010; 12:483-504. [PubMed: 20730641]

Takayanagi Y, Yoshida M, Bielsky IF, Ross HE, Kawamata M, Onaka T, Yanagisawa T, Kimura T, Matzuk MM, Young LJ, et al. Pervasive social deficits, but normal parturition, in oxytocin receptor-deficient mice. Proc Natl Acad Sci USA. 2005; 102:16096-16101. [PubMed: 16249339]

Tribollet E, Charpak S, Schmidt A, Dubois-Dauphin M, Dreifuss JJ. Appearance and transient expression of oxytocin receptors in fetal, infant, and peripubertal rat brain studied by autoradiography and electrophysiology. J Neurosci. 1989; 9:1764-1773. [PubMed: 2542479]

Tronick EZ, Messinger DS, Weinberg MK, Lester BM, Lagasse L, Seifer R, Bauer CR, Shankaran S, Bada H, Wright LL, et al. Cocaine exposure is associated with subtle compromises of infants" and mothers" social-emotional behavior and dyadic features of their interaction in the face-to-face still-face paradigm. Dev Psychol. 2005; 41:711-722. [PubMed: 16173869]

Veenema AH, Neumann ID. Neurobiological mechanisms of aggression and stress coping: a comparative study in mouse and rat selection lines. Brain Behav Evol. 2007; 70:274-285. [PubMed: 17914259]

Vernotica EM, Lisciotto CA, Rosenblatt JS, Morrell JI. Cocaine transiently impairs maternal behavior in the rat. Behav Neurosci. 1996; 110:315-323. [PubMed: 8731058]

Vernotica EM, Rosenblatt JS, Morrell JI. Microinfusion of cocaine into the medial preoptic area or nucleus accumbens transiently impairs maternal behavior in the rat. Behav Neurosci. 1999; 113:377-390. [PubMed: 10357462]

Viviani D, Stoop R. Opposite effects of oxytocin and vasopressin on the emotional expression of the fear response. Prog Brain Res. 2008; 170:207-218. [PubMed: 18655884]

Weisman O, Zagoory-Sharon O, Feldman R. Oxytocin administration to parent enhances infant physiological and behavioral readiness for social engagement. Biol Psychiatry. 2012; 72:982989. [PubMed: 22795645]

Wells K. Substance abuse and child maltreatment. Pediatr Clin North Am. 2009; 56:345-362. [PubMed: 19358920]

Williams SK, Barber JS, Jamieson-Drake AW, Enns JA, Townsend LB, Walker CH, Johns JM. Chronic cocaine exposure during pregnancy increases postpartum neuroendocrine stress responses. J Neuroendocrinol. 2012; 24:701-711. [PubMed: 22309318]

Williams SK, Cox ET, McMurray MS, Fay EE, Jarrett TM, Walker CH, Overstreet DH, Johns JM. Simultaneous prenatal ethanol and nicotine exposure affect ethanol consumption, ethanol preference and oxytocin receptor binding in adolescent and adult rats. Neurotoxicol Teratol. 2009; 31:291-302. [PubMed: 19539752]

Williams, SK.; Jamieson-Drake, AW.; Barber, JS.; Radcliffe, M.; Walker, CH.; Johns, JM. Gestational cocaine exposure: effects on brain region oxytocin levels in postpartum rat mothers following pup retrieval or forced swimming. World Congress on Neurohypophyseal Hormones; 2011a.

Williams SK, Lauder JM, Johns JM. Prenatal Cocaine Disrupts Serotonin Signaling-Dependent Behaviors: Implications for Sex Differences, Early Stress and Prenatal SSRI Exposure. Curr Neuropharmacol. 2011b; 9:478-511. [PubMed: 22379462]

Williams, SK.; Walker, CH.; Johns, JM. Oxytocin system measures in young rat pups: dependence on early environmental exposures. Boston, MA. New York Academy of Sciences Behavioral Epigenetics Meeting; 2010.

Wood RD, Spear LP. Prenatal cocaine alters social competition of infant, adolescent, and adult rats. Behav Neurosci. 1998; 112:419-431. [PubMed: 9588488]

Wood RD, Bannoura MD, Johanson IB. Prenatal cocaine exposure: effects on play behavior in the juvenile rat. Neurotoxicol Teratol. 1994; 16:139-144. [PubMed: 8052187]

Wood RD, Molina VA, Wagner JM, Spear LP. Play behavior and stress responsivity in periadolescent offspring exposed prenatally to cocaine. Pharmacol Biochem Behav. 1995; 52:367-374. [PubMed: 8577803]

Yamasue H, Yee JR, Hurlemann R, Rilling JK, Chen FS, Meyer-Lindenberg A, Tost H. Integrative approaches utilizing oxytocin to enhance prosocial behavior: from animal and human social behavior to autistic social dysfunction. J Neurosci. 2012; 32:14109-14117. [PubMed: 23055480] 
Yanowitch R, Coccaro EF. The neurochemistry of human aggression. Adv Genet. 2011; 75:151-169. [PubMed: 22078480]

Yoshida M, Takayanagi Y, Inoue K, Kimura T, Young LJ, Onaka T, Nishimori K. Evidence that oxytocin exerts anxiolytic effects via oxytocin receptor expressed in serotonergic neurons in mice. J Neurosci. 2009; 29:2259-2271. [PubMed: 19228979]

Young WS, Shepard E, Amico J, Hennighausen L, Wagner KU, LaMarca ME, McKinney C, Ginns EI. Deficiency in mouse oxytocin prevents milk ejection, but not fertility or parturition. J Neuroendocrinol. 1996; 8:847-853. [PubMed: 8933362]

Zimmerberg B, Gray MS. The effects of cocaine on maternal behaviors in the rat. Physiol Behav. 1992; 52:379-384. [PubMed: 1523266] 


\section{Highlights}

- Gestational cocaine exposure disrupts maternal care and oxytocin in the postpartum

- Prenatal cocaine alters the oxytocin-driven aggression, stress and parental care.

- Exposure to cocaine-exposed mothers disrupts offspring social behavior and oxytocin

- Altered maternal care and oxytocin may lead to intergenerational transmission of drug abuse 


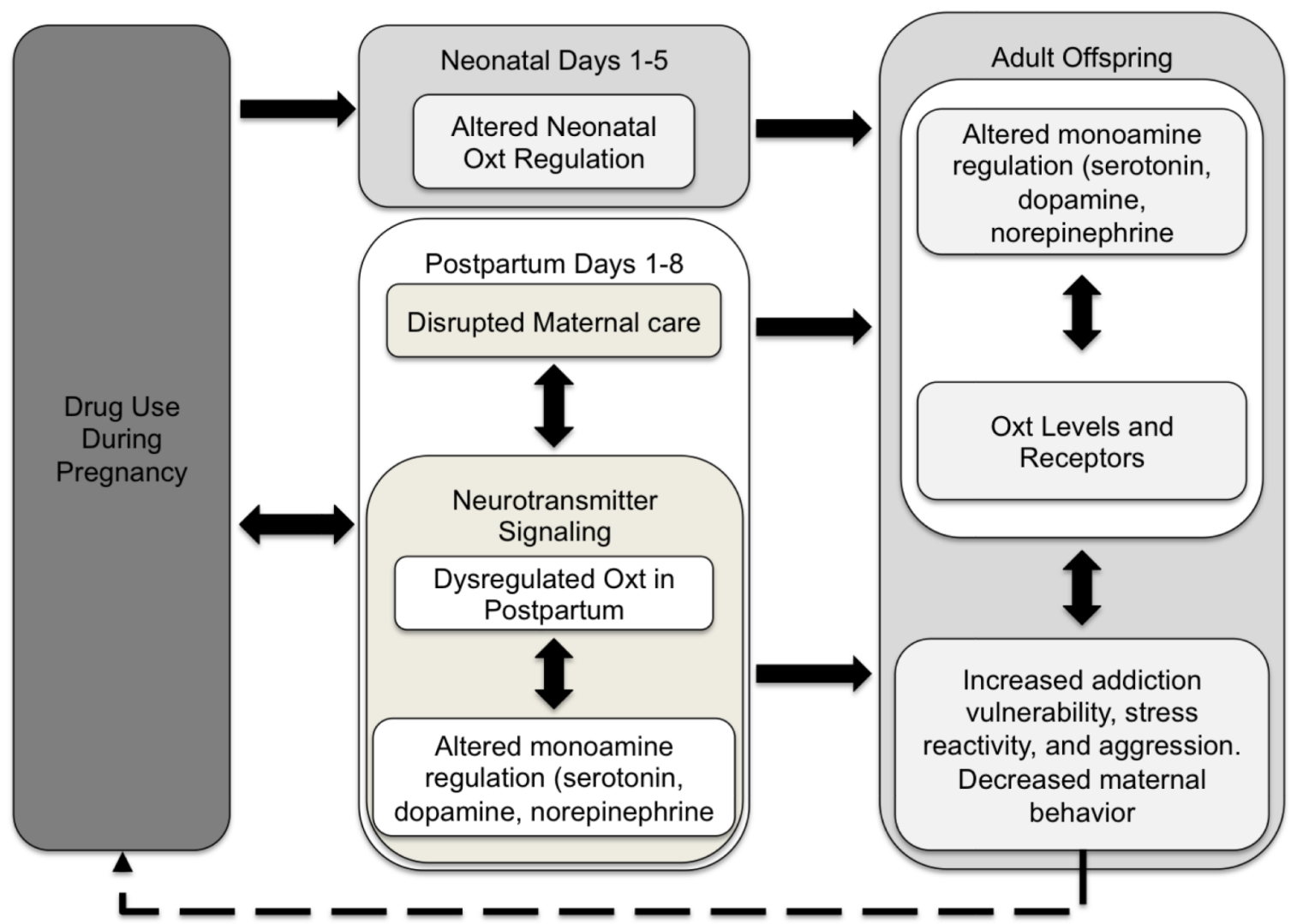

Figure 1.

Intergenerational Transmission of Addiction through Disrupted Oxytocin. Drug use during pregnancy results in negative outcomes for neonatal pups (Top box in center) as well as disrupted Oxt signaling and poor maternal care. Independently, either of these outcomes can be responsible for altered Oxt and monoaminergic signaling and resulting behavioral deficits in adult offspring. Phenotypes of offspring could result in addiction and drug use during pregnancy in the next generation, perpetuating a cycle of oxytocin deficits (dashed arrow). 


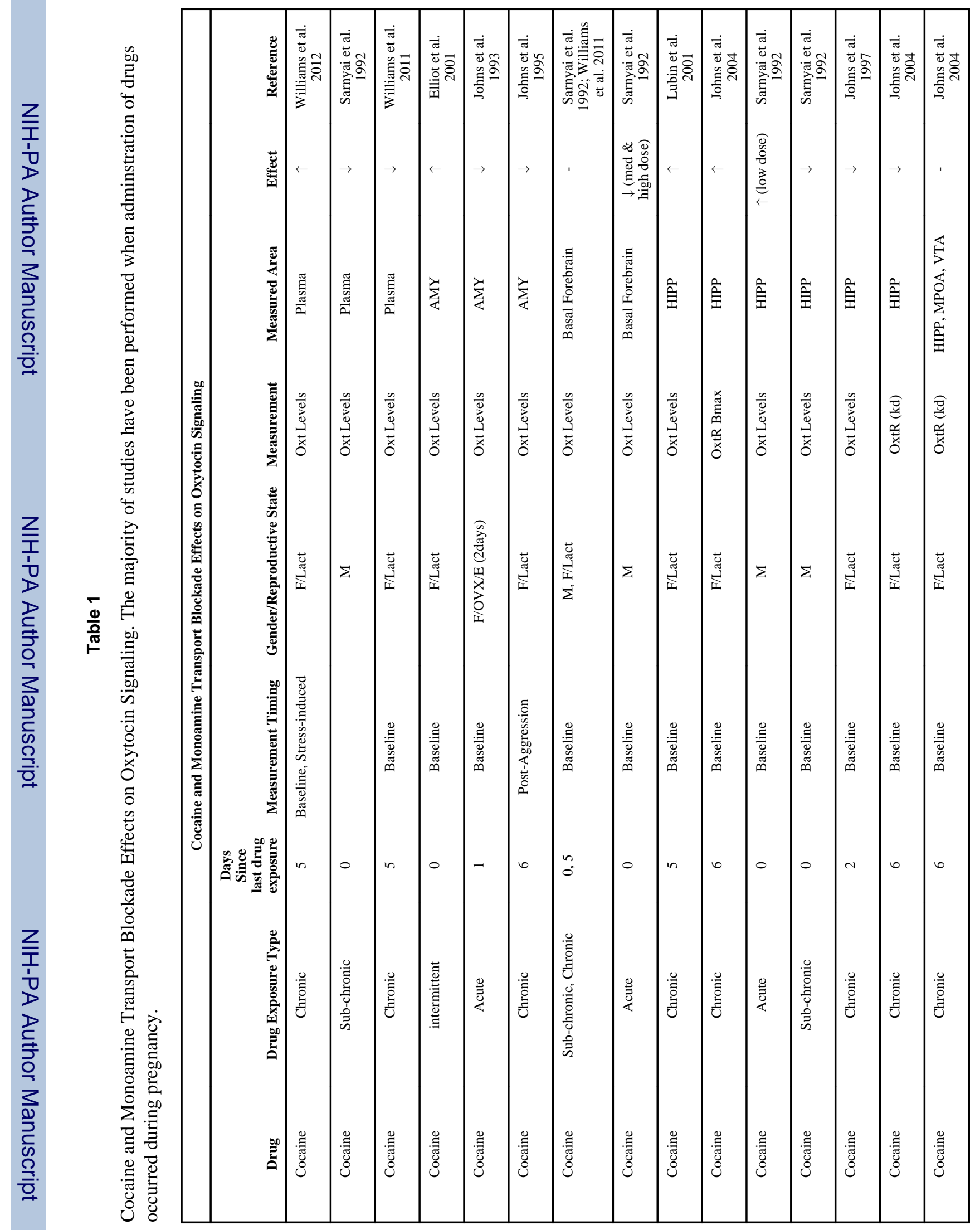

Pharmacol Biochem Behav. Author manuscript; available in PMC 2015 April 01. 


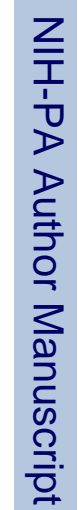

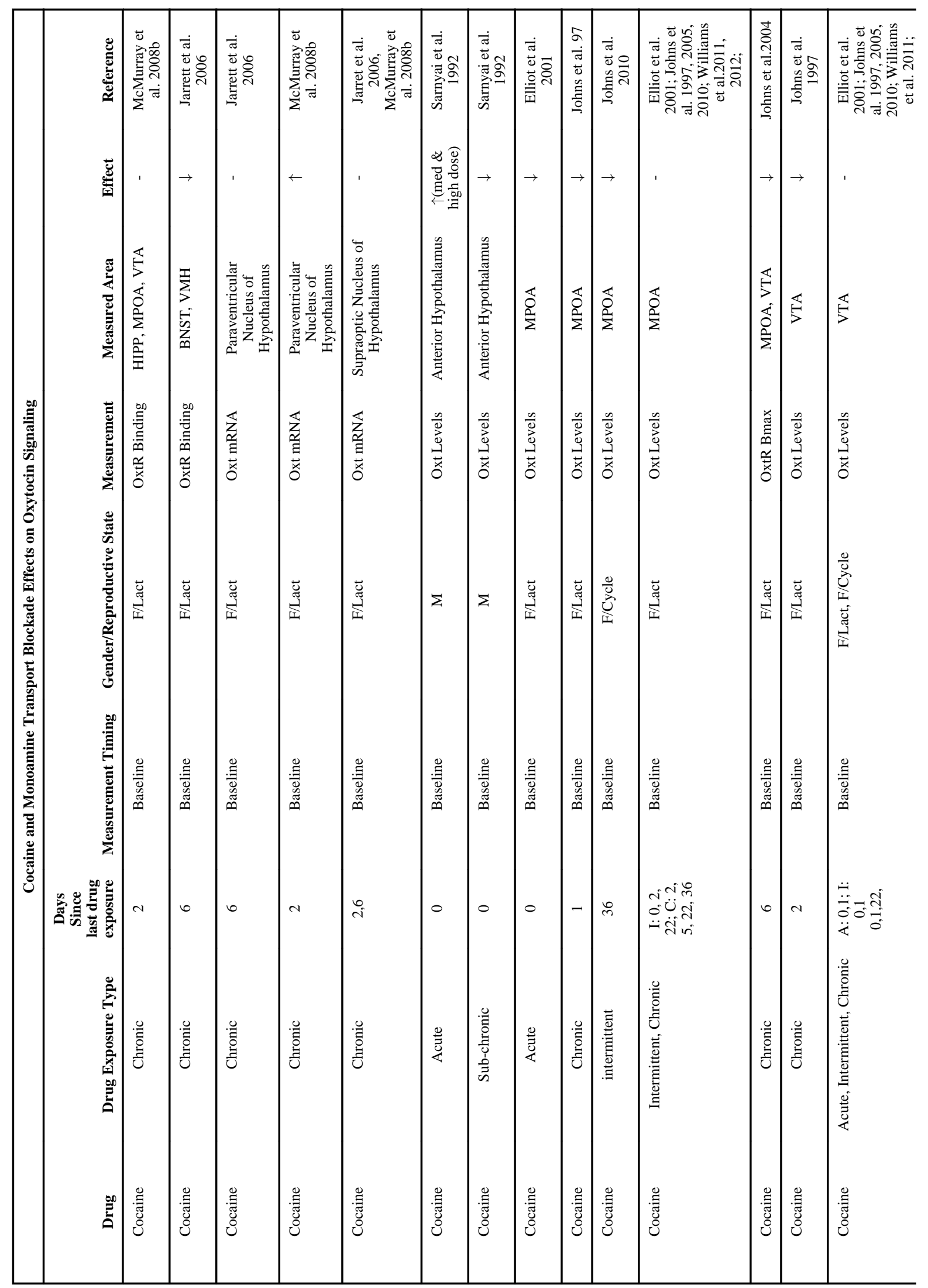

Pharmacol Biochem Behav. Author manuscript; available in PMC 2015 April 01. 


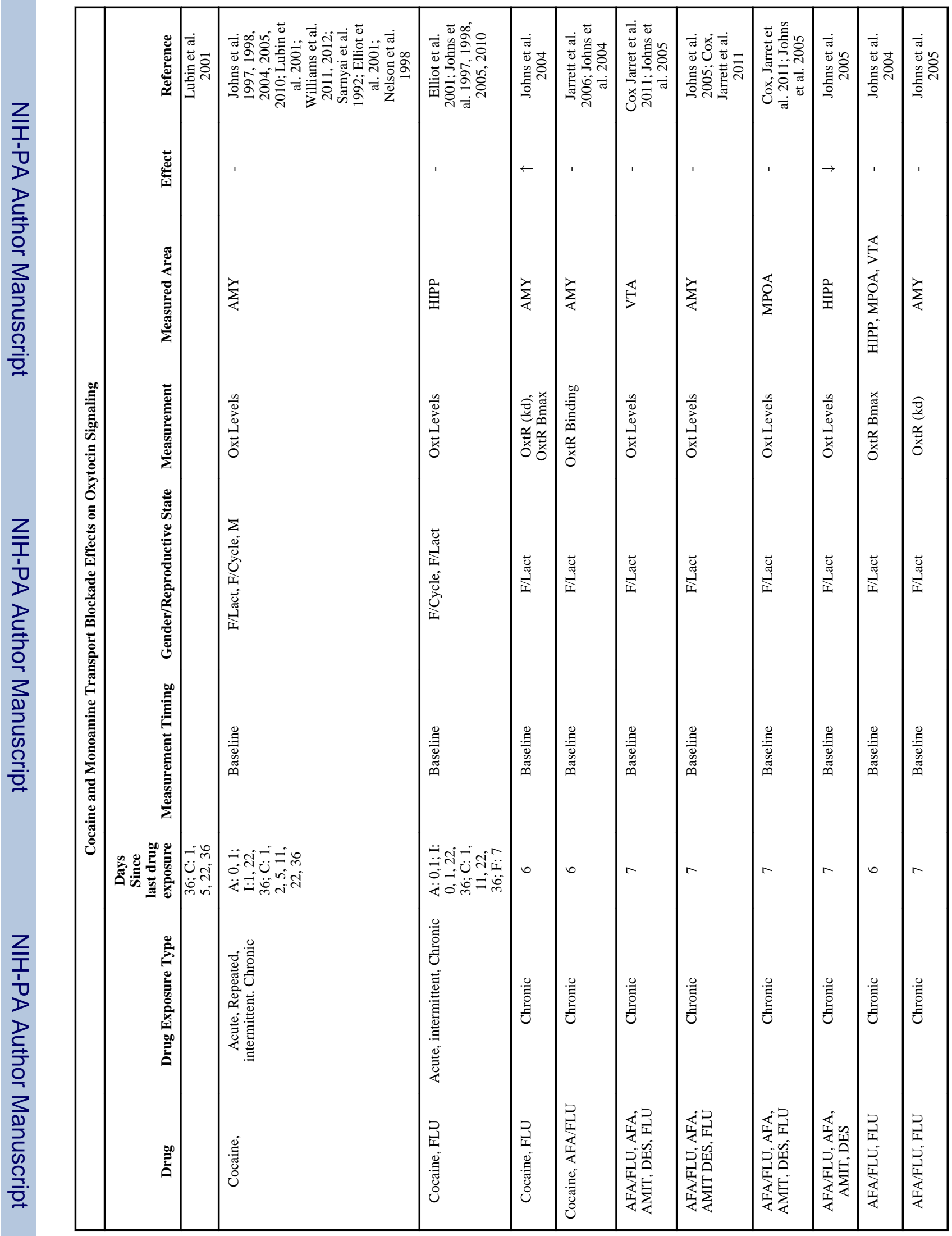

Pharmacol Biochem Behav. Author manuscript; available in PMC 2015 April 01. 


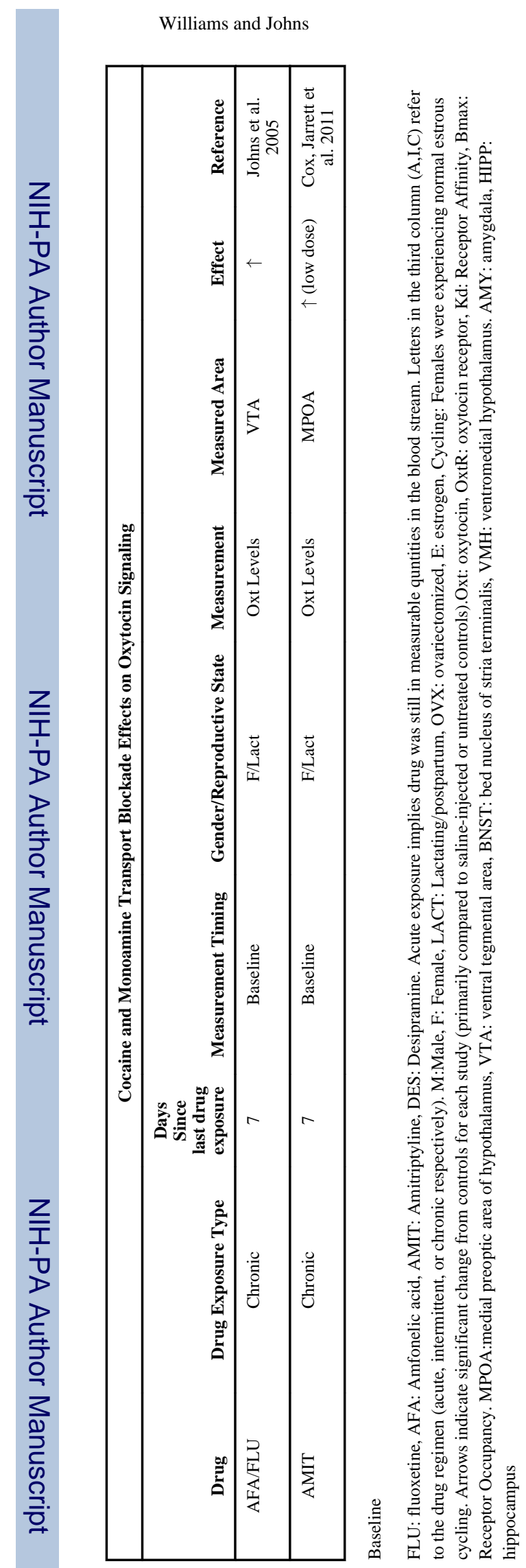

Pharmacol Biochem Behav. Author manuscript; available in PMC 2015 April 01. 


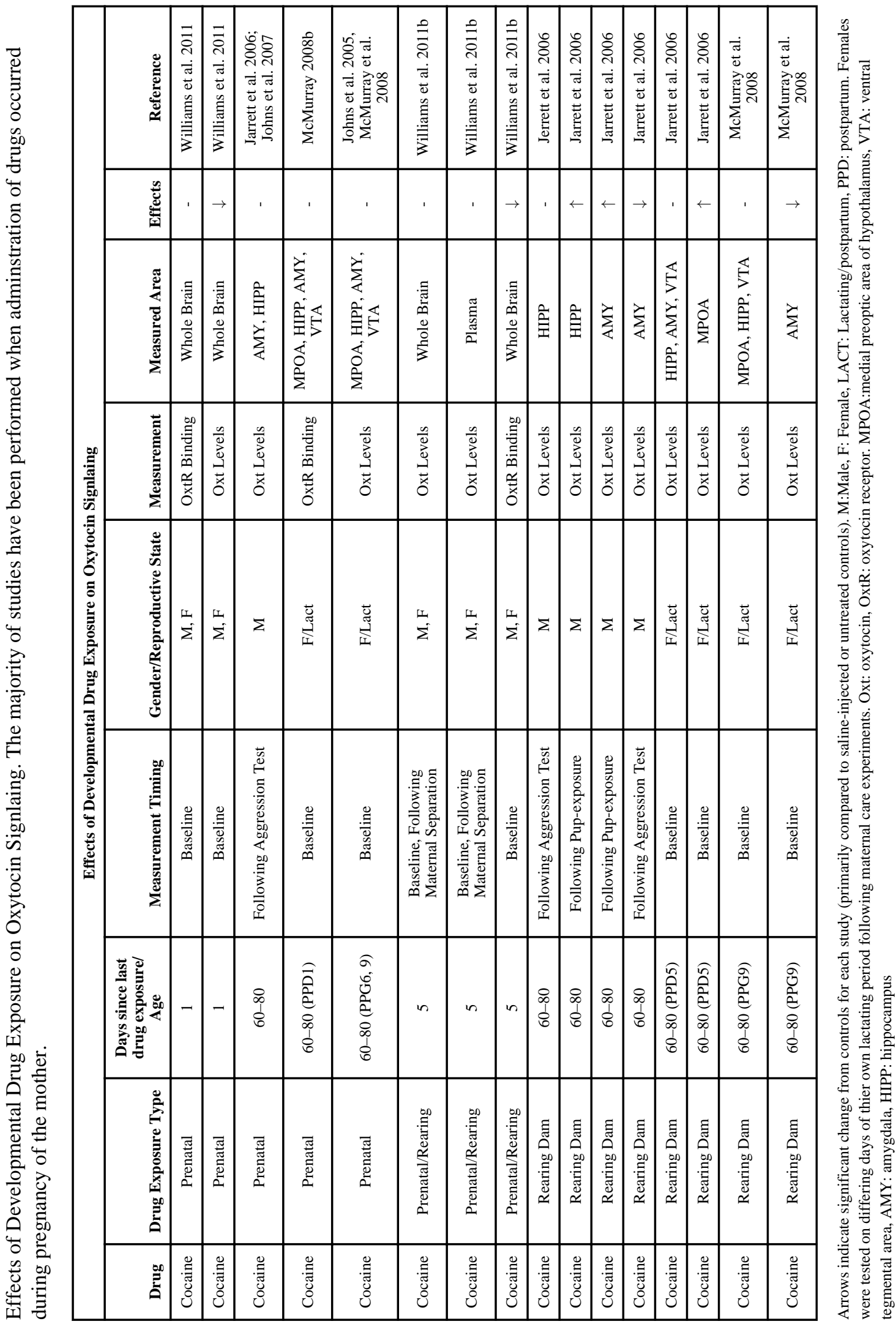

